\title{
Determination of Sensitivity and Specificity of High Resolution CT Scan in Evaluation of Cardiac and Extra- Cardiac Anomalies among Bangladeshi Children
}

\author{
M. Shirin, R. Mondal, and H. Zubery
}

\section{ABSTRACT}

\begin{abstract}
Congenital heart disease (CHD) is one of the important causes of morbidity and mortality in the pediatric age group. Invasive angiography is considered as gold standard method for the diagnosis of pediatric cardiovascular diseases. Multi-detector CT cardiac angiogram by using 64 slice scanner is a useful modality and suitable alternative to previous invasive procedure in evaluation of congenital heart disease. The present study was conducted in the Department of Cardiology of NICVD during the period of September 2019 to August 2020 (One year). We selected 40 patients presenting in the outpatient department of National Institute of Cardiovascular Diseases and Hospital (NICVD) who were diagnosed to have congenital heart disease clinically and radiologically. CT angiogram revealed ASD in 10\%, coarctation of aorta in 5\%, Pentalogy of Fallot in $\mathbf{2 . 5 \%}$, Tetralogy of Fallot (TOF) in 32.5\%, Ventricular septal defect (VSD) in $30.0 \%$, PAH in $2.5 \%$, PS in $5 \%$, RVH with PS in $2.5 \%$, PDA in $5 \%$ and Tricuspid atresia with ASD with VSD with PS in $2.5 \%$ patients. Conventional catheter angiogram revealed ASD in 5\%, VSD in 32.5\%, TOF in $30 \%$, PS in $12.5 \%$, Coarctation of aorta in $5 \%$ and Pentalogy of Fallots in 5\%. The diagnostic performance of MDCT in the diagnosis and evaluation of congenital heart disease was high.
\end{abstract}

Keywords: Computed tomography, congenital heart disease, echocardiography.

\section{INTRODUCTION}

Mitchell et al. stated CHD as "a gross structural abnormality of the heart or intrathoracic great vessels that is actually or potentially of functional significance" [1]. Congenital heart disease (CHD) is an important cause of morbidity and mortality of the pediatric age group. Incidence of CHD is almost similar throughout the globe which is about $10 / 10,000$ live births. There is no exact data available for the incidence and prevalence of CHD in Bangladesh. It is assumed that currently of about 3 lac CHD patients are there in Bangladesh. Every year 13,000 new cases are added to this pool. About $50 \%$ of children are dying within one year if not being managed properly. So early and accurate diagnosis with appropriate treatment is very mandatory for management of the cases. Moreover cost- effective and patient friendly diagnostic modality is a necessity for patients both from the biologic and socio-economic points of view according to Mitchell et al. [1].

Catheter angiography is the standard of reference for the assessment and evaluation of congenital heart disease and an invasive with potentially hazardous procedure having a small number of risks of serious events (e.g., Arrhythmia, Stroke, Coronary artery dissection \& Death). Furthermore, the catheterization procedure necessitates admission of the
Published Online: December 13, 2021

ISSN: $2736-5476$

DOI: $10.24018 /$ ejclinicmed.2021.2.6.146

\section{Shirin*}

Bangabandhu Sheikh Mujib Medical University, Bangladesh.

(e-mail: m.shirin1970@gmail.com)

R. Mondal

National Institute of Cardiovascular Diseases and Hospital, Bangladesh.

(e-mail: rathin021@gmail.com)

H. Zubery

Rajshahi Medical College Hospital, Bangladesh.

(e-mail: mohammadzubery@gmail.com)

*Corresponding Author patient in hospital and potential discomfort as stated. Accuracy of catheter cardio angiography is also limited by the overlapping of adjacent major mediastinal vascular structures, difficulty in demonstrating systemic and pulmonary vascular systems simultaneously and separately, catheter-related complications (especially in young children), and relatively high doses of ionizing radiation as well as iodinated contrast media. Therefore, conventional angiography should be undertaken strictly on specific clinical indications. Echocardiography is useful for diagnostic, preoperative evaluation and postoperative follow up of congenital heart diseases but having some limitations including poor acoustic window, limited depiction of extracardiac vascular structures, small field of view and dependence upon operator. Some of these limitations are encountered by Magnetic Resonance Imaging (MRI), especially in evaluation of both the anatomic and functional assessment of the heart, but it is time-consuming and requires a longer period of patient sedation; therefore, the use of MR in seriously ill or uncooperative patients is certainly limited. Computed tomography (CT) has important roles in overcoming these limitations. CT can be used in the morphologic evaluation of congenital heart disease (CHD) according to [2]-[5].

Ultrafast computed tomography (CT) scanners allow quick non-invasive evaluation of the cardiovascular system, 
virtually eliminating the need for prolonged sedation. The development of 64-slice CT with increased scanning speed, higher spatial resolution, and enhanced capabilities for simultaneous evaluation of cardiovascular structures and lung parenchyma, has important roles in overcoming some limitations for the evaluation of patients with congenital heart disease as stated by [2]-[6].

For this instance, 64 slice CT cardiac angiography have been used because of their fast image acquisition times and their capacity to obtain volumetric data. Cardiac imaging with $\mathrm{CT}$ and MR imaging always relies on technical developments because high temporal and spatial resolution is necessary for satisfactory evaluation of CHD according to [3], [5].

Cardiac catheterization is an invasive and expensive method for evaluation of cardiac defect. These add substantial complexities in very young patients with congenital heart disease. Minimally invasive imaging modality like 64 Slice CT Angiography in the setting of appropriate clinical indications could lead to a significant reduction of unnecessary diagnostic cardiac catheterizations and of the costs and complications associated with the method stated by [7]. This study was designed to see the accuracy and superior effectiveness as well as to address the relative risks and benefits of minimally invasive MDCT over the conventional invasive method of detection of CHD with echocardiography. So, our main objective is to determine the accuracy of 64 Slice CT cardiac Angiography in diagnosing congenital heart disease in children against gold standard conventional fluoroscopic angiography.

\section{METHODS}

The cross-sectional study was carried out among the patients attending in the outpatient department of National Institute of Cardiovascular Diseases and Hospital (NICVD), Department of Paediatric Cardiology of NICVD and Department of Radiology and Imaging of NICVD who were clinically and echocardiographically diagnosed as to have congenital heart disease from September 2019 to August 2020. The study was approved by the ethical committee of Bangabandhu Sheikh Mujib Medical University (BSMMU), Dhaka. A written informed consent was obtained from each parent or legal guardian of the patients. For both modalities (64 Slice CT Angiography and conventional angiography) background characteristics were analyzed using a bi-variate technique. Categorical diagnosis and dichotomous diagnostic variables were created for both modalities and cross tabulated to evaluate accuracy of 64 Slice CT Angiography. Sensitivity, specificity, positive predictive values (PPV) and negative predictive values (NPV) were calculated for 64 Slice CT Angiography taking conventional angiography as the gold standard.

\section{Results}

The mean $( \pm \mathrm{SD})$ age of the patients was $9.4( \pm 4.8)$ years with a range of $1.5-18$ years. Out of 40 patients $22(55.6 \%)$ were male and $18(45 \%)$ were female. Male-female ratio was 11:9. Heart rate (88-140) and haemoglobin concentration (9$18.6 \mathrm{gm} / \mathrm{dl})$ were measured.

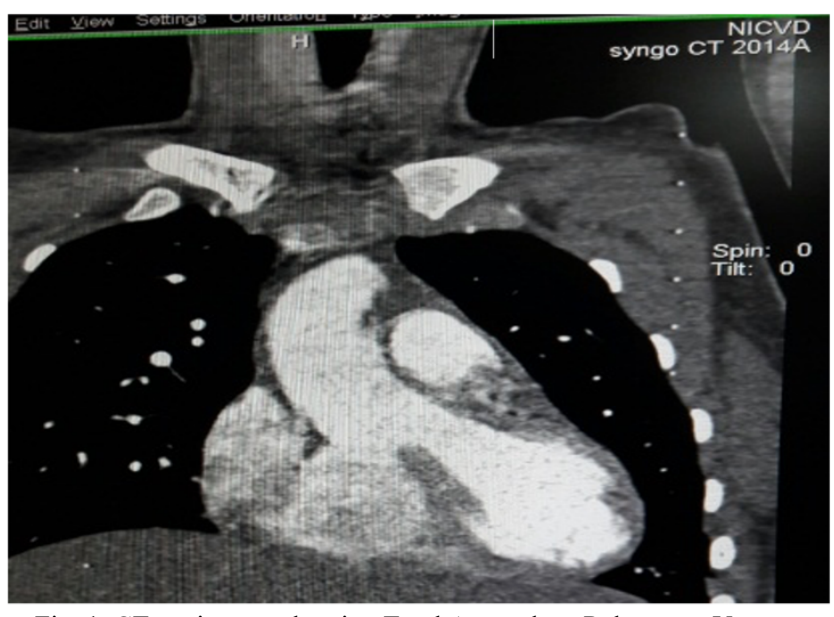

Fig. 1. CT angiogram showing Total Anomalous Pulmonary Venous Drainage (TAPVD).

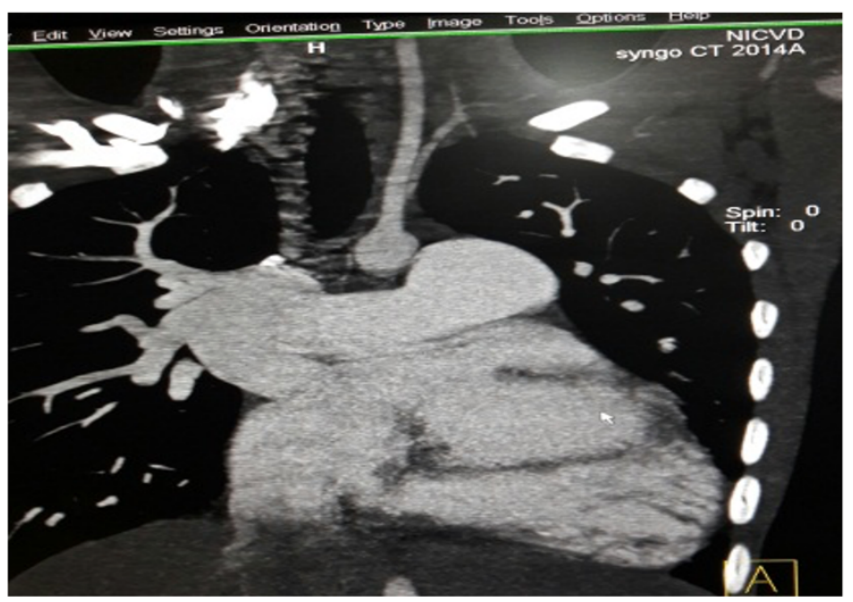

Fig. 2. CT angiogram showing about $50 \%$ overriding of aorta of a patient with TOF.

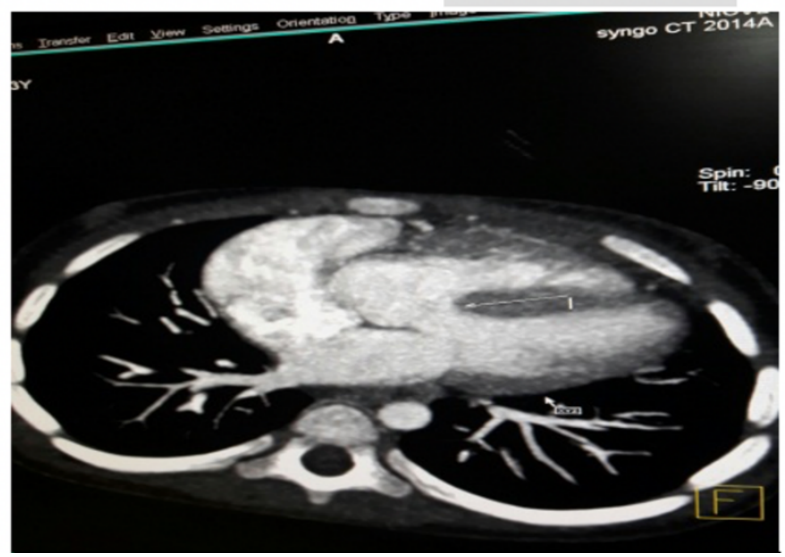

Fig. 3. CT angiogram showing Ventricular Septal Defect (VSD) of a patient with TOF.

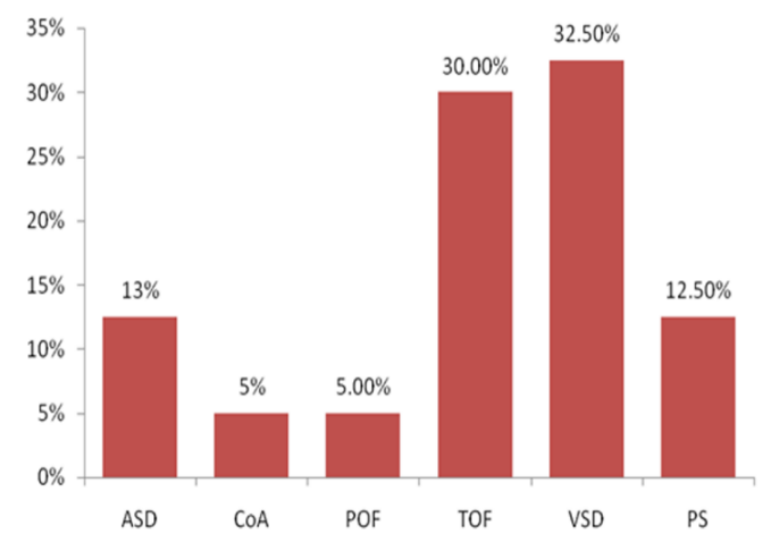

Fig. 4. Bar diagram showing CT cardiac angiogram. 


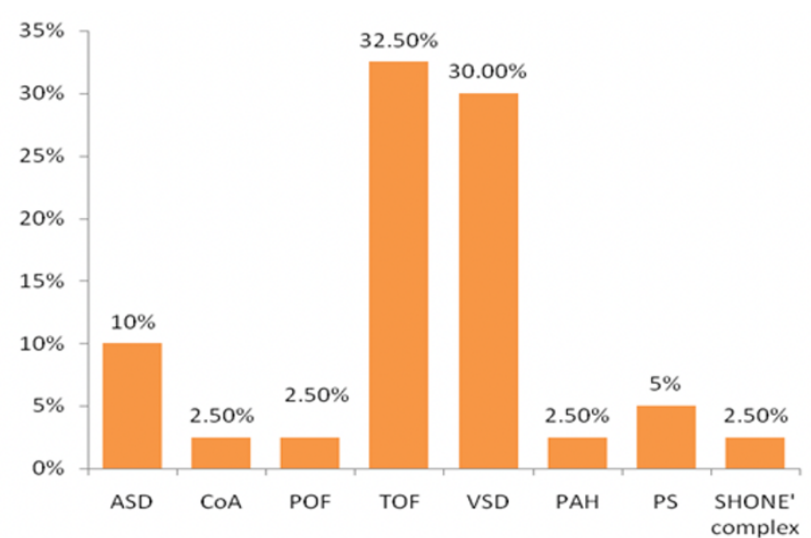

Fig. 5. Bar diagram showing conventional catheter cardiac angiogram diagnosis.

TABLE I: DiAgNOSTIC PERFORMANCE OF MDCT IN TETRALOGY OF FALLOTS (TOF)

\begin{tabular}{cccc}
\hline \hline \multirow{2}{*}{ CT angiogram } & \multicolumn{3}{c}{ Conventional Catheter Angiogram } \\
\cline { 2 - 4 } & Present & Absent & Total \\
\hline \hline \multirow{2}{*}{ Present } & $11(27.5 \%)$ & $2(5 \%)(\mathrm{FP})$ & $13(32.5 \%)$ \\
& $(\mathrm{TP})$ & $(\mathrm{TP}+\mathrm{FP})$ \\
\multirow{2}{*}{ Absent } & $3(7.5 \%)(\mathrm{FN})$ & $24(60 \%)$ & $27(67.5 \%)$ \\
& $14(35 \%)$ & $(\mathrm{TN})$ & $(\mathrm{FN}+\mathrm{TN})$ \\
\multirow{2}{*}{ Total } & $(\mathrm{TP}+\mathrm{FN})$ & $(\mathrm{FP}+\mathrm{TN})$ & \\
& & & \\
\end{tabular}

$\mathrm{TP}=$ true positive, $\mathrm{FP}=$ false positive, $\mathrm{FN}=$ false negative, $\mathrm{TN}=$ true negative.

Statistical analysis for performance of MDCT CA for

Tetralogy of Fallots (TOF) revealed the following results:

Sensitivity $=\mathrm{TP} /(\mathrm{TP}+\mathrm{FN})=11 / 14=78.6 \%$

Specificity $=\mathrm{TN} /(\mathrm{FP}+\mathrm{TN})=24 / 26=92.3 \%$

Positive predictive value $=\mathrm{TP} /(\mathrm{TP}+\mathrm{FP})=11 / 13=84.6 \%$

Negative predictive value $=\mathrm{TN} /(\mathrm{TN}+\mathrm{FN})=24 / 27=88.9 \%$

Accuracy/efficacy $=(\mathrm{TP}+\mathrm{TN}) /$ total

population $=35 / 40=87.5 \%$

TABLE II: DiAgNOSTIC PERFORMANCE OF MDCT IN VENTRICULAR SEPTAL DEFECT (VSD)

\begin{tabular}{|c|c|c|c|}
\hline \multirow{2}{*}{$\begin{array}{c}\mathrm{CT} \\
\text { angiogram }\end{array}$} & \multicolumn{3}{|c|}{ Conventional Catheter Angiogram } \\
\hline & Present & Absent & Total \\
\hline Present & $12(30 \%)(\mathrm{TP})$ & $1(2.5 \%)(\mathrm{FP})$ & $\begin{array}{c}13(32.5 \%) \\
(\mathrm{TP}+\mathrm{FP})\end{array}$ \\
\hline Absent & $1(2.5 \%)(\mathrm{FN})$ & $26(65 \%)(\mathrm{TN})$ & $\begin{array}{c}27(67.5 \%) \\
(\mathrm{FN}+\mathrm{TN})\end{array}$ \\
\hline Total & $\begin{array}{c}13(32.5 \%) \\
(\mathrm{TP}+\mathrm{FN})\end{array}$ & $\begin{array}{c}27(67.5 \%) \\
(\mathrm{FP}+\mathrm{TN})\end{array}$ & $40(100.0 \%)$ \\
\hline
\end{tabular}

$\mathrm{TP}=$ true positive, $\mathrm{FP}=$ false positive, $\mathrm{FN}=$ false negative, $\mathrm{TN}=$ true negative.

TABLE III: DIAGNOSTIC PERFORMANCE OF MDCT CA FOR VENTRICULAR SEPTAL DEFECT (VSD)

\begin{tabular}{cccccc}
\hline \hline Sensitivity & Specificity & $\begin{array}{c}\text { Positive } \\
\text { predictive } \\
\text { value }\end{array}$ & $\begin{array}{c}\text { Negative } \\
\text { predictive } \\
\text { value }\end{array}$ & $\begin{array}{c}\text { Accuracy } \\
\text { or } \\
\text { efficacy }\end{array}$ \\
\hline \hline (VSD) & $92.3 \%$ & $96.3 \%$ & $92.3 \%$ & $96.3 \%$ & $95 \%$ \\
\hline \hline
\end{tabular}

TABLE IV: DiAgNOSTIC PERFORMANCE OF MDCT IN ATRIAL SEPTAL DEFECT (ASD)

\begin{tabular}{|c|c|c|c|}
\hline \multirow{2}{*}{$\begin{array}{c}\mathrm{CT} \\
\text { angiogram }\end{array}$} & \multicolumn{3}{|c|}{ Conventional Catheter Angiogram } \\
\hline & Present & Absent & Total \\
\hline Present & $4(10.0 \%)(\mathrm{TP})$ & $\begin{array}{c}1(2.5 \%) \\
(\mathrm{FP})\end{array}$ & $5(12.5 \%)(\mathrm{TP}+\mathrm{FP})$ \\
\hline Absent & $\begin{array}{c}1(2.5 \%) \\
(\mathrm{FN})\end{array}$ & $\begin{array}{c}34(85 \%) \\
(\mathrm{TN})\end{array}$ & $\begin{array}{c}35(87.5 \%) \\
(\mathrm{FN}+\mathrm{TN})\end{array}$ \\
\hline Total & $5(12.5 \%)(\mathrm{TP}+\mathrm{FN})$ & $\begin{array}{c}35(87.5 \%) \\
(\mathrm{FP}+\mathrm{TN})\end{array}$ & $(100.0 \%)$ \\
\hline
\end{tabular}

$\mathrm{TP}=$ true positive, $\mathrm{FP}=$ false positive, $\mathrm{FN}=$ false negative, $\mathrm{TN}=$ true negative.
TABLE V: Diagnostic Performance of MDCT CA IN AtRial SEPTAL DEFECT (ASD)

\begin{tabular}{cccccc}
\hline \hline Sensitivity & Specificity & $\begin{array}{c}\text { Positive } \\
\text { predictive } \\
\text { value }\end{array}$ & $\begin{array}{c}\text { Negative } \\
\text { predictive } \\
\text { value }\end{array}$ & $\begin{array}{c}\text { Accuracy } \\
\text { or efficacy }\end{array}$ \\
\hline \hline (ASD) & $80 \%$ & $97.1 \%$ & $80 \%$ & $97.1 \%$ & $95 \%$ \\
\hline
\end{tabular}

TABLE VI: DIAGNOSTIC PERFORMANCE OF MDCT IN PULMONARY STENOSIS

\begin{tabular}{cccc}
\multicolumn{4}{c}{ STENOSIS } \\
\cline { 2 - 4 } CT angiogram & \multicolumn{3}{c}{ Conventional Angiogram } \\
\cline { 2 - 4 } Present & $8(20 \%)$ & Absent & Total \\
& $(\mathrm{TP})$ & $1(2.5 \%)(\mathrm{FP})$ & $9(22.5 \%)$ \\
Absent & $2(5 \%)(\mathrm{FN})$ & $29(72.5 \%)$ & $31(77.5 \%)$ \\
\multirow{2}{*}{ Total } & $10(25 \%)$ & $30(75 \%)$ & $(\mathrm{FN}+\mathrm{TN})$ \\
& $(\mathrm{TP}+\mathrm{FN})$ & $(\mathrm{FP}+\mathrm{TN})$ & $40(100.0 \%)$ \\
\hline \hline
\end{tabular}

$\mathrm{TP}=$ true positive, $\mathrm{FP}=$ false positive, $\mathrm{FN}=$ false negative, $\mathrm{TN}=$ true negative.

TABLE VII: Diagnostic PERFormanCE of MDCT CARDiAC ANGIOGRAM FOR PULMONARY STENOSIS

\begin{tabular}{cccccc}
\hline \hline & $\begin{array}{c}\text { Sensiti- } \\
\text { vity }\end{array}$ & $\begin{array}{c}\text { Specifi- } \\
\text { city }\end{array}$ & $\begin{array}{c}\text { Positive } \\
\text { predictive } \\
\text { value }\end{array}$ & $\begin{array}{c}\text { Negative } \\
\text { predictive } \\
\text { value }\end{array}$ & $\begin{array}{c}\text { Accuracy } \\
\text { or } \\
\text { efficacy }\end{array}$ \\
\hline \hline $\begin{array}{c}\text { (Pulmonary } \\
\text { stenosis) }\end{array}$ & $80 \%$ & $96.6 \%$ & $88.9 \%$ & $93.5 \%$ & $92.5 \%$ \\
\hline \hline
\end{tabular}

TABLE VIII: DiAgNOSTIC PERFORMANCE OF MDCT IN PULMONARY ARTERY HYPERTENSION (PAH)

\begin{tabular}{cccc}
\hline \hline CT & \multicolumn{3}{c}{ Conventional Angiogram } \\
\cline { 2 - 4 } angiogram & Present & Absent & Total \\
\hline \hline Present & $4(10 \%)(\mathrm{TP})$ & $1(2.5 \%)(\mathrm{FP})$ & $5(12.5 \%)(\mathrm{TP}+\mathrm{FP})$ \\
Absent & $1(2.5 \%)(\mathrm{FN})$ & $34(85 \%)(\mathrm{TN})$ & $35(87.5 \%)$ \\
& & $35(87.5 \%)$ & $(\mathrm{FN}+\mathrm{TN})$ \\
Total & $5(12.5 \%)(\mathrm{TP}+\mathrm{F})$ & $(\mathrm{FP}+\mathrm{TN})$ & $40(100.0 \%)$ \\
& &
\end{tabular}

TABLE IX: Diagnostic PERFormance OF MDCT CA FOR PULMONARY ARTERY HYPERTENSION (PAH)

\begin{tabular}{cccccc}
\hline \hline Sensitivity & Specificity & $\begin{array}{c}\text { Positive } \\
\text { predictive } \\
\text { value }\end{array}$ & $\begin{array}{c}\text { Negative } \\
\text { predictiv } \\
\text { e value }\end{array}$ & $\begin{array}{c}\text { Accuracy } \\
\text { or } \\
\text { efficacy }\end{array}$ \\
\hline \hline (PAH) & $80 \%$ & $97.1 \%$ & $80 \%$ & $97.1 \%$ & $95 \%$ \\
\hline \hline
\end{tabular}

\begin{tabular}{cccc}
\multicolumn{4}{c}{ TABLE X: DiAgNOSTIC PERFORMANCE OF MDCT IN PATENT DUCTUS } \\
ARTERIOSUS(PDA) \\
\hline \multirow{2}{*}{ CT angiogram } & \multicolumn{3}{c}{ Conventional Angiogram } \\
\cline { 2 - 4 } & Present & Absent & Total \\
\hline \multirow{2}{*}{ Present } & $4(10 \%)$ & $0(0.0 \%)$ & $4(10 \%)$ \\
& $(\mathrm{TP})$ & $(\mathrm{FP})$ & $(\mathrm{TP}+\mathrm{FP})$ \\
Absent & $1(2.5 \%)$ & $35(87.5 \%)$ & $36(90 \%)$ \\
& $(\mathrm{FN})$ & $(\mathrm{TN})$ & $(\mathrm{FN}+\mathrm{TN})$ \\
Total & $5(12.5 \%)$ & $35(87.5 \%)$ & $40(100.0 \%)$ \\
& $(\mathrm{TP}+\mathrm{FN})$ & $(\mathrm{FP}+\mathrm{TN})$ & \\
\hline \hline
\end{tabular}

TABLE XI: DiAgNOSTIC PERFORMANCE OF MDCT CA FOR PATENT DUCTUS ARTERIOSUS(PDA)

\begin{tabular}{cccccc||}
\hline \hline Sensitivity & Specificity & $\begin{array}{c}\text { Positive } \\
\text { predictiv } \\
\text { e value }\end{array}$ & $\begin{array}{c}\text { Negative } \\
\text { predictive } \\
\text { value }\end{array}$ & $\begin{array}{c}\text { Accuracy } \\
\text { or } \\
\text { efficacy }\end{array}$ \\
\hline \hline (PDA) & $80 \%$ & $100 \%$ & $100 \%$ & $97.2 \%$ & $97.5 \%$ \\
\hline \hline
\end{tabular}

\section{DISCUSSION}

The CT cardiac angiogram diagnoses of congenital heart disease were as follows: Tetralogy of Fallot (TOF) was diagnosed in $32.5 \%$ patient and pentalogy of Fallot in $2.5 \%$ patients. Ventricular septal defect (VSD) was found in $30.0 \%$ patients with associated PDA in $2.5 \%$, PS in 5\%, PDA and PAH in $2.5 \%$ patients. Moderate pulmonary artery hypertension was present in $1(2.5 \%)$ patient, PS in $2(5 \%)$ 
patients and RVH with PS in 1 (2.5\%) patient. ASD was found in $10 \%$ patients, $7.5 \%$ with associated pulmonary artery hypertension and $2.5 \%$ with pulmonary stenosis. $5 \%$ patients had coarctation of aorta. Moderate size PDA with dilated coronary sinus was present in $2(5 \%)$ patients and Tricuspid atresia with ASD with VSD with severe pulmonary stenosis was present in $1(2.5 \%)$ patient. Conventional catheter cardiac angiogram diagnosis was as follows: ASD $12.5 \%$ cases with associated pulmonary hypertension in $4(10 \%)$ cases and pulmonary hypertension with PDA in $1(2.5 \%)$ case. VSD was found in $13(32.5 \%)$ cases with associated PDA in $1(2.5 \%)$ case, PDA with PAH in $1(2.5 \%)$ case, AR with PS in $1(2.5 \%)$ case and PS in $2(5 \%)$ cases. TOF was present in $12(30 \%)$ cases, PS in $5(12.5 \%)$ cases, Coarctation of aorta was present in $2(5 \%)$ cases and Pentalogy of Fallots was present in $2(5 \%)$ cases. Our findings are supported by [8]-[10] who found almost similar result like us.

Reference [8] studied a total of 103 patients and observed a total of 163 intracardiac deformities and 260 extracardiac anomalies. The intracardiac deformities visualized includes ventricular septal defect (VSD), Atrial Septal Defect (ASD), Complete Endocardial Cushion Defect (CECD), Single ventricle, Hypoplastic left heart, right ventricular hypertrophy, and Dextrocardia. Out of total 260 extracardiac anomalies Transposition of the great arteries (TGA), Doubleoutlet ventricle, Truncus arteriosus, aortic striding, Anomalous Pulmonary Venous Connection (APVC), Pulmonary venous stenosis, Pulmonary artery stenosis, pulmonary artery atresia, aortic coarctation, anomalous aortic origin or pulmonary artery origin (such as aberrant subclavian artery, double aortic arches, dextroaortic arch, pulmonary artery sling), Patent Ductus Arteriosus (PDA) and abnormal coronary artery were detected. A total of 154 of $163(94.48 \%)$ intracardiac deformities were demonstrated by CTA by [8].

Reference [9] studied 91,823 children and found spectrum of congenital heart defects (CHD) are follows, ventricular septal defect (VSD) (31.41\%), atrial septal defect (ASD) $(11.37 \%)$, aortic stenosis (AS) (7.64\%), pulmonary stenosis (PS) $(7.13 \%)$, coarctation of the aorta $(\mathrm{CoA})(5.77 \%)$, and transposition of the great arteries (TGA) $(5.43 \%)$, followed by persistent ductus arteriosus (PDA) (4.75\%), atrio ventricular septal defect (AVSD) and hypoplastic left heart syndrome (HLHS) (4.07\% each), tetralogy of Fallot (TOF) $(3.56 \%)$ and pulmonary atresia (PA) $(2.38 \%)$.

In a retrospective epidemiological analysis of congenital anomalies [10] found that $36 \%$ of children born with a congenital anomaly in the Czech Republic during the period of 1994 - 2008. CHD most frequently diagnosed in births were congenital malformations of cardiac septa of about $55 \%$ of all CHD and congenital malformations of great arteries were more than $18 \%$. A rate of prenatally diagnosed case was $11.35 \%$ in discordant ventriculoarterial connection, $8.35 \%$ in discordant atrioventricular connection, $49.41 \%$ in hypoplastic left heart syndrome, $7.64 \%$ in coarctation of aorta and $9.71 \%$ in tetralogy of Fallot. These anomalies were parts of chromosomal syndromes in $42.58 \%$ and non-chromosomal syndromes in $9.33 \%$.

The sensitivity and specificity of 64 slice CT scan were $78.6 \%$ and $92.3 \%$ in diagnosis of TOF, $92.3 \%$ and $96.3 \%$ in diagnosis of VSD, $80 \%$ and $97.1 \%$ in diagnosis of ASD and
$\mathrm{PAH}$, and $80 \%$ and $96.6 \%$ in diagnosis of PS. Our findings nearly similar to [8].

Reference [8] showed the clinical value of 64-slice CT scanner in diagnosis of complicated CHD in 103 neonates and infants who were clinically diagnosed as complicated CHD. The accuracy rates of CTA in detecting deformities of complicated CHD were $97.16 \%$. The sensitivity of CTA was $97.40 \%$ and the specificity of CTA was $99.76 \%$ respectively. In case of extracardiac and intracardiac deformity the accuracy rates of CTA were $97.0 \%$. Reference [8] stated that CTA with a 64-slice CT is a credible technique for diagnosis of complicated CHD in neonates and infants. After initial screening and assessment with echocardiography, CTA can be used for further accurate and detailed clarifications.

Regarding diagnostic performance of MDCT cardiac angiogram for patent ductus arteriosus (PDA) were sensitivity $80 \%$, specificity $100 \%$, positive predictive value $100 \%$, negative predictive value $97.2 \%$ and accuracy $97.5 \%$. The sensitivity in our study is slightly higher than the sensitivity of the study conducted by [11]. We found 1 false negative and no false positive PDA. However, [11] found 2 false-negative and 1 false-positive PDA during their study. Reference [11] explained that the cause of one false-negative PDA finding was very small $(1 \mathrm{~mm})$ diameter of the artery, which was clearly detected by cardiac angiography and was considered to be due to the limited CT resolution. The cause of the other false negative PDA finding was due to the difficulty in detecting PDA as there was adhesion of the top margin of the enlarged left branch of the pulmonary artery with the bottom margin of the aortic arch despite the relatively large PDA (diameter about $7 \mathrm{~mm}$ ). Regarding the single false-positive PDA finding was due to pulsation artifact of the aorta produced by the beating heart and was erroneously diagnosed as PDA. These findings indicate that MDCT is very helpful imaging technique for PDA. But MDCT has certain limitations, and the findings should be confirmed by cardiac catheter angiography according to [11]. Sometimes CT angiography may be the superior modality over conventional angiography regarding in some critical and complex issues. During performing catheter angiogram in complex congenital defects and critical stenosis, it becomes difficult or impossible to pass the catheter beyond the stenosed part due to technical and anatomical deformities. In those cases, CT angiography helps to visualize the complex anatomy as well as pathology, which not only help to reduce the patients' discomfort and complications associated with conventional angiogram but also reduces the monetary cost. CT angiography also helps to visualize the peripheral $1 / 3$ of the pulmonary vessels. In our study, one case was diagnosed as 'SHONE complex' where congenital mitral stenosis (parasite like deformity of mitral valve), aortic stenosis (bicuspid aortic valve), coarctation of the aorta and PDA were noted. Coarctation of the aorta was located between the origin of the left common carotid artery and left subclavian artery.

Conventional angiogram only visualizes proximal onethird, but CT angiogram visualize more peripheral part of the pulmonary artery, so evaluation of peripheral pulmonary atresia can only be done by CT angiogram. The prognosis dependents on the level and degree of obstruction. So before going to surgery it is important to visualize properly the level and degree of pulmonary obstruction which can affect the 
prognosis of the patients by CT angiogram.

\section{CONCLUSION}

Diagnostic modality like 64 slice CT Cardiac Angiography is being upgraded every day. The resolution capacity and accuracy to diagnose CHD is reaching near perfection using these emerging technologies. The sensitivity, specificity, positive predictive value, negative predictive value, and accuracy for MDCT angiogram was as high as conventional angiogram and sometime superior to catheter angiogram in some complex CHD. This non or minimally invasive modality requires less sedation, less time, less complication, and less radiation hazard. This modality can replace other diagnostic modality to increase diagnostic performance.

\section{REFERENCES}

[1] Mitchell SC, Korones SB, Berendes HW. Congenital heart disease in 56,109 births. Incidence and natural history. Circulation. 1971; 43: 323-32.

[2] Kawano T, Ishii M, Takagi J, Maeno Y, Eto G, Sugahara Y, et al. Three-dimensional helical computed tomographic angiography in neonates and infants with complex congenital heart disease. American Heart Journal. 2020; 139(4): 653-660.

[3] Moon Y, Kim YM, Kim TH, Kim MY, Lee JY, Kim HS. Congenital anomalies of aortic arch: CT angiography. Journal of the Korean Society of Radiology. 2001; 44: 51-58.

[4] Becker C, Soppa C, Fink U, Haubner M, Müller-Lisse,U, Englmeier $\mathrm{KH}$, et al. Spiral $\mathrm{CT}$ angiography and $3 \mathrm{D}$ reconstruction in patients with aortic coarctation. European Radiology. 1997; 7(9): 1473-1477.

[5] Haramati LB, Glickstein FS, Issenberg HF, Haramati N, Crooke GA. MR imaging and CT of vascular anomalies and connections in patients with congenital heart disease: significance in surgical planning. Radio Graphics. 2002; 22: 337-349.

[6] Ulla M, Abramzon FA, Monaco RDG. 64 row CT angiography: diagnosing paediatric CVD disease. HIRE. 2008; 3: 2-4.

[7] Budoff MJ, Lu B, Shinbane JS, Chen L, Child J, Carson S, et al. Methodology for improved detection of coronary stenoses with computed tomographic angiography. American Heart Journal. 2004; 148(6): 1085-1090.

[8] Ruan W, Yang MN, Gong Y, Qiao L, Mo X, Teng G. Diagnosis of complicated congenital heart diseases in neonates and infants using 64slice spiral CT. Scientific Research and Essays. 2011; 6: 146-156.

[9] Samanek M, Slavík Z, Zborilova B, Hrobonova V, Vorískova M, Skovranek J. Prevalence, treatment, and outcome of heart disease in live-born children: a prospective analysis of 91,823 live-born children. Pediatric Cardiology. 1989; 10: 205-11.

[10] Sipek A, Gregor V, Sipek A Jr, Hudakova J, Horacek J, Klaschka J, et al. Incidence of congenital heart defects in the Czech Republic--current data. Ceska Gynekol's. 2010; 75: 221-42.

[11] Kani H, Narabayashi I, Tanikake M, Matsuki M, Uesung Y. Usefulness of Multidetector-row Computed Tomography (MD-CT) for Diagnosis and Evaluation of Cardiovascular Anomalies in Infants. Bulletin of the Osaka Medical College 2005; 51: 23-34. 